\title{
CONTRIBUIÇÕES DO PROJETO PILOTO À COLETA DE DADOS EM PESQUISAS NA ÁREA DE EDUCAÇÃO ${ }^{1}$
}

\author{
Luis Henrique SILVA ${ }^{2}$ \\ Anna Augusta Sampaio OLIVEIRA ${ }^{3}$
}

RESUMO: No presente artigo tratamos da importância do Projeto Piloto como recurso fundamental para análise do planejamento e dos procedimentos que serão adotados na construção de fontes verdadeiramente científicas através de entrevistas na área de educação. Para tanto, apresentamos toda a trajetória de planejamento, aplicação, análise e reestruturação das entrevistas que utilizamos como recurso para coleta de dados em uma dissertação de Mestrado cujo foco foi a análise da concepção do êxito no ensino de história para alunos com deficiência intelectual em uma Diretoria Regional de Educação do interior do Estado do São Paulo. Os resultados demonstraram que a entrevista é de fato um importante recurso para coleta de dados em pesquisas que envolvem a participação de alunos com deficiência intelectual e seus respectivos professores, porém, necessita ser amplamente planejada de forma a reduzir a chance de interferência de diversos fatores que, por suas características, são capazes de comprometer a amostra e, consequentemente, a fidedignidade esperada nos trabalhos acadêmicos.

PALAVRAS-CHAVE: Entrevista. Recurso. Projeto-Piloto.

\section{Introdução}

Como criar condições ideais para acesso a fontes indispensáveis ao desenvolvimento do conhecimento científico quando essas não são documentais? Como garantir que a construção destas fontes se dê de forma adequada e que resulte em dados verdadeiramente seguros do ponto de vista científico principalmente quando utilizamos a entrevista como recurso?

Breve análise das produções científicas nas universidades brasileiras pode demonstrar que ela tem sido correntemente utilizada, porém, esta preocupação metodológica quanto à sua construção, desde o planejamento sobre quem e como entrevistar, que perguntas fazer e ainda se de fato é o recurso mais adequado diante do problema que se quer discutir, não transparece de forma efetiva.

É certo que a falta do registro não é fator determinante no impedimento do alcance de excelentes resultados em diversos trabalhos de alta qualidade que vêm

\footnotetext{
${ }^{1}$ Financiado pela Fundação de Amparo à Pesquisa do Estado de São Paulo.

2 Diretor do Colégio Ressurreição Santa Maria. Assis - SP. Doutorando em Educação. UNESP Universidade Estadual Paulista. Faculdade de Filosofia e Ciências - Pós-Graduação em Educação. Marília - SP - Brasil. 17525-900 - lhsilva1 @yahoo.com.br

${ }^{3}$ Vice-coordenadora do Programa de Pós-Graduação em Educação. UNESP - Universidade Estadual Paulista. Faculdade de Filosofia e Ciências - Departamento de Educação Especial. Marília - SP - Brasil. 17525-900 - hanamel@terra.com.br
} 
gradualmente ampliando o desenvolvimento do conhecimento científico nacional, porém, preocupa-nos sua falta na medida em que cerceia ao leitor o acesso a informações preciosas acerca dos cuidados quanto à garantia de total cientificidade no processo de construção das fontes que o edificaram.

Neste sentido, a grande pergunta que nos move, de origem notavelmente epistemológica, visa a problematizar este processo de construção especificamente quando do uso da entrevista como recurso de coleta de dados com alunos com deficiência intelectual, afinal, esta se dá na interação direta entre partícipe e coletor; contato social naturalmente cercado de ansiedades, preconceitos, medos, enfim, uma vasta quantidade de fatores que inquestionavelmente tem profundo potencial de intervenção nos resultados.

Acreditando na importância da discussão como fator indispensável para uma maior qualidade da produção científica brasileira, apresentamos o Projeto Piloto como ferramenta que pode ser utilizada neste desejoso processo reflexivo acerca do planejamento das ações que resultarão na entrevista.

A ideia inicial é a de que ele pode contribuir largamente neste processo reflexivo que compreendemos ser fundamental para o desenvolvimento de qualquer projeto que se apóia em entrevistas, proporcionando assim, melhores condições para que principalmente os que acabam de adentrar os percursos da ciência nacional, tenham cada vez melhores condições de planejamento, execução e defesa dos resultados que se dispuseram a buscar.

Mas o que exatamente seria um Projeto Piloto?

Trata-se de um instrumento capaz de reproduzir eficazmente e em escala reduzida parte significativa dos meios que serão encontrados pelo pesquisador no momento definitivo de coleta de dados.

Analisa-se através dele, especificamente, questões relacionadas aos procedimentos de aplicação do recurso selecionado para coleta dos dados a partir de uma amostra resultante de sua efetiva utilização em uma pequena seleção de participantes, visando proporcionar condições de reflexão quanto à sua viabilidade, adequação à proposta e principalmente sua cientificidade.

Constituindo o sentido deste artigo, apresentamos primeiramente quais as condições que determinaram na ocasião do desenvolvimento da dissertação referenciada, a opção pela utilização da entrevista como recurso de coleta de dados. 
Após detalhar as características que determinaram esta opção, apresentamos todas as diretrizes que inicialmente fundamentaram a seleção dos participantes do projeto piloto e o desenvolvimento do instrumento (planilha e sequiência de perguntas) para conduzir a coleta de dados.

Descritos os procedimentos iniciais, apresentamos com grandes detalhes como se deu a execução das entrevistas e todo o processo analítico sobre cada item que nos pareceu significativo quanto ao seu potencial de intervenção sobre os resultados, bem como, os procedimentos que tomamos para reformular tanto o sequenciamento de perguntas quanto os cuidados indispensáveis no momento de abordagem do entrevistado.

Esta preocupação fundamenta-se nos expressivos debates promovidos por importantes pesquisadores na área da Educação Especial (OLIVEIRA, 2003; DIAS; OMOTE, 1990, 1995), buscando a sustentabilidade metodológica fundamental para a produção do conhecimento científico.

\section{Por que entrevistar?}

Consideramos essencial realizar a seleção do recurso de coleta de dados para o desenvolvimento do trabalho proposto somente após conhecimento da quantidade, características e localização dos grupos participantes, pois somados às peculiaridades do objeto sob investigação, estes dados indicariam detalhes importantes sobre as condições de sua aplicação.

Analisados estes itens percebemos que a proposta de estudo demandaria naturalmente o conhecimento sobre vários aspectos inerentes à subjetividade dos participantes, pois as experiências sociais distintas poderiam constituir consideráveis diferenças entre as concepções de êxito no ensino de história.

Além de possibilitar o estudo desta subjetividade, a análise também indicou que o recurso deveria possibilitar grande flexibilidade à constituição das fontes, considerando as características distintas dos grupos participantes e a garantia de ampla possibilidade de colaboração.

Diante destas diretrizes, a entrevista pareceu-nos a melhor opção, pois além de ser reconhecidamente importante instrumento de pesquisa (DIAS; OMOTE, 1995) contribuindo à realização de diversos estudos referentes à subjetividade humana (OLIVEIRA, 2003), permite importante planejamento anterior à sua execução, garantindo: 
a. Adequação da linguagem de acordo com as características do participante.

b. Redução da possibilidade de esquecimento quanto à realização de perguntas indispensáveis à compreensão do objeto sob investigação.

c. Padronização de procedimentos, possibilitando identificação de elementos significativos de interferência na fase de coleta de dados, que podem comprometer sua análise.

Além destas garantias, observamos também que o recurso estava adequado e permitia forte aproveitamento através do método de análise dos dados que escolhemos àquele momento, ou seja, a Análise Textual Discursiva, Moraes (2003), visto que permitia elaboração de "Metatextos", ou seja, extratos significativos da fala dos participantes, que ofereceriam subsídios científicos para toda a análise proposta.

\section{Como entrevistar?}

Visando aos procedimentos ideais para constituição adequada destes "Metatextos" a partir das entrevistas, construímos inicialmente um detalhado roteiro de perguntas como proposta inicial.

Partimos do contexto de onde afinal parte toda nossa proposta, ou seja, a educação e a escola. Considerando ambos enquanto expressões históricas e culturais de onde emerge o homem (BRUNER, 1987 apud MOLL, 1996), e reconhecendo nelas o importante espaço de promoção da inserção cultural deste homem e de sua capacidade de significação do mundo a partir dos processos de mediação (VYGOTSKY, 1999; PADILHA, 2004), edificamos o roteiro de perguntas dividido em dois momentos que denominamos condições anteriores e posteriores às ações de inclusão dos alunos com deficiência intelectual nas escolas regulares estudadas.

Tendo em vista que o trabalho desenvolvido focava o momento de encontro entre alunos com e sem deficiência na escola, resultado das ações internacionais de promoção da equidade de acesso e permanência aos espaços comuns de escolarização, o roteiro de perguntas deveria proporcionar condições de compreensão das forças atuantes na construção deste momento, e com ele, a concepção sobre êxito no ensino de história que era o objetivo de nossa análise.

Neste sentido, propomos que sua estrutura inicial abordasse esses dois momentos, deixando claras as diferenças iniciais, o encontro e os conflitos provenientes deste, ou seja, buscamos compreender o movimento de sua constituição, já que nossa perspectiva teórica nos orientava que: 
la esencia de las cosas es la dialéctica de las cosas, y ésta se revela en la dinámica, en el proceso del movimiento, del cambio, de la formación y de la destrucción, en el estudio de la génesis y el desarrollo. (VYGOTSKY, 1997, p.170).

Sendo assim, para os alunos participantes da pesquisa, as perguntas foram então estruturadas compreendendo:

Condições iniciais enquanto percepção sobre a organização do espaço a ser encontrado pelo aluno, o que contempla seu conceito sobre escola, professores, aprendizagem e disciplinas escolares.

Condições posteriores enquanto percepção do aluno quanto à organização do espaço escolar após sua frequência, contemplando aspectos referentes à sua concepção quanto ao método de ensino do professor, sobre êxito na aprendizagem de história e suas próprias perspectivas quanto à aprendizagem.

O quadro representava uma reflexão inicial, construída como lembra Moraes (2003) a partir das leituras e significações do pesquisador quanto ao seu próprio objeto de estudo e de suas fontes.

\section{Quem entrevistar?}

Visando à validação do método e dos instrumentos definidos para a constituição das fontes, selecionamos um aluno participante (A1) para ser submetido a todos os procedimentos previstos, visando responder às seguintes perguntas: a disposição do espaço e os procedimentos para realização da entrevista garantem segurança e confiabilidade das fontes? As perguntas que constituem o instrumento são adequadas para a compreensão do fenômeno estudado?

\section{Análise da entrevista com o aluno}

$\mathrm{O}$ contato inicial com A1 foi realizado na sua residência quando, junto à sua mãe, nos recebeu para apresentação pessoal e exposição dos objetivos do projeto.

Nessa apresentação, foi possível perceber certo incômodo por parte de A1 e sua mãe quanto ao conceito utilizado pelo pesquisador para remeter-se ao público participante.

O projeto bem como os documentos produzidos a partir de seus objetivos, como por exemplo, o Termo de Consentimento Livre e Esclarecido, apresentavam até então o conceito "Deficiência Mental". Apesar de ter percebido a inadequação e corrigido em 
um segundo momento para "Deficiência Intelectual", percebemos a continuidade do incômodo mesmo não sendo verbalizado por ambos.

Quando novamente substituído o conceito por "criança com necessidades educacionais especiais" percebemos o acolhimento dos participantes, desencadeando longa discussão sobre o conceito de diferença no sistema regular de ensino.

Este primeiro contato demonstra de forma detalhada que a entrevista, como lembra Dias e Omote (1995) é um importante processo de interação face a face e não simplesmente uma técnica de coleta de dados, demandando uma série de cautelas por parte do pesquisador quanto à sua estruturação e condução, já que:

O jogo de papéis e as expectativas, tanto do entrevistador, quanto do entrevistado, desempenham forte influência na determinação da fala de cada um, das informações a serem levantadas e, portanto, da eficácia ou não da entrevista como instrumento válido para coleta de dados, numa perspectiva cientificamente correta. (OLIVEIRA, 2003, p.28).

A entrevista foi realizada na sala da residência, tendo inicio às 15 horas e 5 minutos e término às 15 horas e 10 minutos, sendo atentamente e em sua totalidade acompanhada pela mãe de A1.

Observando a disposição deste espaço, não nos parecia ocorrer qualquer fato que pudesse constituir algum impedimento ou frustração no alcance dos resultados melhor e fielmente expressos pelo entrevistado.

Porém, durante análise da transcrição, fortes indícios de interferência decorrentes desta interação apontada por Dias e Omote (1995) foram gradativamente desvelados, indicando a necessidade de revisão de alguns procedimentos para realização da entrevista e constituição deste espaço.

O primeiro item de interferência foi resultante da presença da mãe de A1 durante a realização da entrevista e pode ser observado na pergunta 7 , que aborda a opção pessoal pelas disciplinas escolares, conforme segue:

E - Qual matéria você gosta mais?

A1 - Que eu gosto mais [...] Educação Física.

E - Perfeito. Por que você gosta mais de Educação Física?

A1 - Porque é mais melhor! [risos]

MÃE - [risos] não faz nada [risos]

A significativa manifestação (grifo) traz importantes indícios quanto à constituição de papéis e expectativas indicadas por Oliveira (2003), que neste exemplo 
nos mostra não limitar-se ao entrevistador e seu entrevistado, mas a todos os presentes no ambiente de realização da entrevista.

Após o julgamento negativo diante da resposta, percebemos a constante preocupação do entrevistado com a presença de sua mãe, já que observava sua reação a cada resposta, o que nos leva a concluir que houve comprometimento da entrevista.

A clara interferência provocada pela verbalização da mãe demonstra ainda que a simples presença de um terceiro, mesmo não interagindo diretamente, tem potencial de comprometimento do resultado da entrevista, desta forma, concluímos que durante sua realização, devem estar presentes somente o entrevistador e seu entrevistado.

Dando continuidade à análise, observamos um segundo importante item de interferência na pergunta 16, que aborda a aprendizagem de história.

E - É. Tenta lembrar alguma coisa que você aprendeu esse ano.

A1 - Ah ... um monte de coisa. Sobre Luiz Teixeira de 1900... essas coisas ...

O personagem criado por A1 enquanto complemento de sua resposta, bem como a função que cumpre na estrutura da frase segue padrões de reprodução do paradigma tradicional do ensino de história.

Segundo Burke (apud CRUZ, 2004, p.80), de acordo com o paradigma tradicional, a história:

[...] refere-se essencialmente à política, adota a narrativa como forma de transmissão do conhecimento, interessa-se principalmente pelos feitos dos "grandes homens", utiliza como fontes os documentos emanados do governo e preservados em arquivos, condiciona as explicações a uma causalidade mecânica, considera a História como conhecimento objetivo, que deve ser apresentada na forma de fatos.

Quando A1 apresenta o personagem Luiz Teixeira e o suposto período histórico onde o mesmo teve importância historiográfica, parece demonstrar a intenção de construir uma resposta escolar correta, através da tradicional reprodução de fato, personagem e data.

A resposta construída por A1 ganha ainda mais sentido quando buscamos a quem possivelmente estaria direcionada esta resposta.

Considerando o contato inicial, quando o pesquisador apresenta-se como professor de história que desenvolve pesquisa sobre o ensino desta disciplina escolar, 
podemos inferir que a resposta de A1, além de corresponder às possíveis expectativas construídas pela mãe, também corresponderia às do professor.

A análise da pergunta 8 , que aborda a matéria que o entrevistado mais gosta, nos mostra os mesmos indícios de interferência:

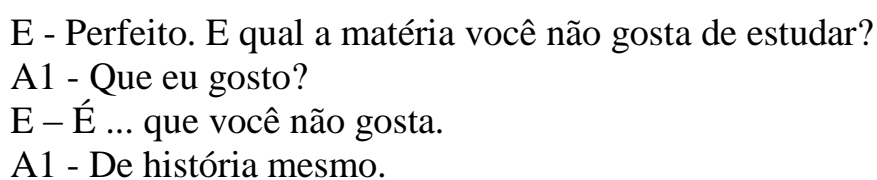

A resposta de A1 reforçada pelo imperativo "mesmo", indica um possível reconhecimento da função profissional do pesquisador, possibilitando-nos concluir que, na pergunta 16, a resposta pode ter sido construída para atender às expectativas do professor a frente do entrevistado, indicando que, de fato, as informações apresentadas no primeiro contato podem comprometer o resultado da amostra.

Visando então evitar possível comprometimento, optamos por limitar a apresentação das funções profissionais do pesquisador no contato inicial com os participantes.

Além da preocupação quanto aos procedimentos de execução da entrevista, empreendemos grande esforço no sentido de garantir cientificidade também no processo de elaboração das perguntas, para que todas sejam estruturadas de forma a trazer à tona as informações necessárias para a compreensão do fenômeno estudado, logo, obrigatoriamente, cumprindo os seguintes requisitos: relevância, clareza e objetividade.

Para a análise das perguntas quanto ao cumprimento destes itens, convidamos três professores graduados e atuantes na área de pesquisa e ensino da disciplina em questão.

Com base nos objetivos do trabalho, os professores foram orientados a julgar através de uma tabela denominada "Quadro de julgamento", cada uma das questões, respondendo: Esta pergunta é relevante, clara e objetiva para a compreensão do objeto sob investigação?

Assinalando "S" para sim e "N" para não, cada professor respondeu individualmente aos itens constantes do quadro, sendo atribuído valor 1 (um) a cada resposta. Não foram pontuados os itens "Clareza" e "Objetividade" daquelas julgadas irrelevantes para o desenvolvimento do estudo.

O resultado da consulta pode ser observado na seguinte tabela: 
Tabela 1 - Resultado da consulta aos professores quanto às perguntas a serem realizadas aos alunos participantes

\begin{tabular}{|c|c|c|c|c|c|c|}
\hline \multirow{2}{*}{ Pergunta } & \multicolumn{2}{|c|}{ Relevância } & \multicolumn{2}{|c|}{ Clareza } & \multicolumn{2}{|c|}{ Objetividade } \\
\hline & $\mathbf{S}$ & $\mathbf{N}$ & $\mathbf{S}$ & $\mathbf{N}$ & $\mathbf{S}$ & $\mathbf{N}$ \\
\hline 1 & 3 & 0 & 3 & 0 & 3 & 0 \\
\hline 2 & 3 & 0 & 3 & 0 & 3 & 0 \\
\hline 3 & 3 & 0 & 3 & 0 & 3 & 0 \\
\hline 4 & 2 & 1 & 2 & 0 & 2 & 0 \\
\hline 5 & 2 & 1 & 2 & 0 & 2 & 0 \\
\hline 6 & 1 & 2 & 1 & 0 & 1 & 0 \\
\hline 7 & 2 & 1 & 2 & 0 & 2 & 0 \\
\hline 8 & 3 & 0 & 3 & 0 & 3 & 0 \\
\hline 9 & 3 & 0 & 3 & 0 & 3 & 0 \\
\hline 10 & 2 & 1 & 2 & 0 & 2 & 0 \\
\hline 11 & 3 & 0 & 3 & 0 & 3 & 0 \\
\hline 12 & 3 & 0 & 3 & 0 & 3 & 0 \\
\hline 13 & 3 & 0 & 3 & 0 & 3 & 0 \\
\hline 14 & 2 & 1 & 2 & 0 & 2 & 0 \\
\hline 15 & 2 & 1 & 2 & 0 & 2 & 0 \\
\hline 16 & 2 & 1 & 1 & 1 & 1 & 1 \\
\hline 17 & 2 & 1 & 2 & 0 & 2 & 0 \\
\hline
\end{tabular}

Fonte: Elaboração própria.

Considerando os resultados apresentados, realizamos revisão individual das perguntas após leitura integral da entrevista, de forma a verificar elementos que indiquem as adequações necessárias apontadas pelos participantes.

As perguntas 1, 2 e 3 obtiveram alto índice de concordância ${ }^{4}$ para os três fatores de análise. Lendo o conteúdo integral das respostas de P1, percebemos que todas foram plenamente compreendidas e respondidas, logo serão mantidas no roteiro.

\footnotetext{
${ }^{4}$ Denominamos alto índice de concordância àquelas perguntas julgadas relevantes pelos três professores
} convidados (3/3). Sequencialmente, denominamos médio índice $(2 / 3)$ e baixo índice $(1 / 3)$. 
Considerando a possibilidade de ampliação da abordagem da pergunta 1, optamos somente pela adição de um pequeno complemento, passando a pergunta a ter a seguinte redação: Você gosta de ir para a escola? Por que você (não) gosta de ir para a escola?

As perguntas 4 e 5 obtiveram médio índice de concordância quanto à relevância para o desenvolvimento da proposta. Entre os votos válidos, houve alto índice quanto à clareza e objetividade da pergunta, o que nos leva a questionar quais os indícios que indicariam um dos votos pela sua irrelevância ao trabalho proposto.

Analisando as perguntas, pudemos perceber que ambas (somando-se a elas também a pergunta 6 , que obteve baixo índice de concordância) cumprem função introdutória visando a contextualizar itens importantes a serem tratados logo à frente no roteiro. Buscando que cumpram mais especificamente esta função, optamos por condensá-las em um só texto introdutório que passa a ter a seguinte redação: Agora nós vamos falar um pouco sobre quem nos ajuda a aprender na escola e o que nós estudamos lá, tudo bem?

A pergunta 7 obteve médio índice de concordância quanto à sua relevância. Visa a revelar um pouco da compreensão do entrevistado quanto às disciplinas escolares e a possível relação existente entre opção pessoal e aprendizagem escolar.

Analisando a resposta de A1 à pergunta, percebemos a tentativa de explicar o motivo que leva à sua opção pela disciplina citada (que poderia ser melhor aproveitada pelo pesquisador no momento da entrevista), logo observamos que cumpre sua função, possibilitando-nos optar pela sua completa manutenção.

As perguntas 8 e 9 ainda buscam informações sobre as opções do participante quanto às disciplinas escolares, tendo, ambas, alcançado alto índice de concordância quanto à relevância para a pesquisa.

As respostas de A1, no entanto, foram evasivas, sendo constituídas de simples reafirmações também observadas nas respostas às perguntas 7,8 e 13:

E - Perfeito. Por que você gosta mais de Educação Física?

A1 - Porque é mais melhor! [risos]

E - De história [risos]. Por quê?

A1 - Porque sim. Não gosto muito... muito difícil.

E - Como você faz pra lembrar o que o professor de história ensinou? A1 - Ah... é difícil...

Estas reafirmações evasivas não foram percebidas pelo pesquisador no momento 
da entrevista, logo, não foram retomadas as perguntas de maneiras distintas visando à garantia da plena compreensão do participante.

Desta forma, concluímos que as perguntas são relevantes, claras e objetivas, logo devendo ser mantidas, porém, demandam especial atenção do pesquisador na coleta definitiva para que seus objetivos sejam de fato alcançados.

A pergunta 10, que obteve médio índice de concordância quanto a sua relevância, também cumpre função introdutória, visando a dar início às primeiras questões referentes ao ensino de história. Diante da resposta de A1, percebemos que tem validade segundo o objetivo para a qual foi designada, parecendo-nos viável apenas adequá-la para melhor cumprir sua função.

Nesse sentido, realizamos sua reestruturação resultando na seguinte redação: Você lembra quem é seu professor de história? Geralmente o professor faz várias coisas na sala de aula para nós aprendermos, não é verdade?

As perguntas 11, 12 e 13 obtiveram alto índice de concordância quanto a sua relevância, tendo as respostas de A1 resultado em ampla e importante fonte de análise, levando-nos a decidir pela sua manutenção sem qualquer adequação.

As perguntas 14 e 16 indicaram médio índice de concordância quanto a sua relevância. São complementares e visam à descrição das percepções do participante quanto ao conceito de bom aluno em história. Considerando a obtenção de excelente material resultante da reflexão de A1 a partir das perguntas, concluímos pela sua manutenção.

A pergunta 15 também indicou médio índice quanto à relevância. Proporciona a descrição da percepção do aluno quanto ao método de ensino utilizado pelo professor de história. Cumpriu perfeitamente sua função, já que a resposta foi longamente descritiva, oferecendo vasto material de análise, desta forma, devendo ser mantida.

Finalmente, quanto à pergunta 17 que obteve médio índice de concordância, percebemos que acabou por perder o seu sentido quando alocada no final do roteiro. Isso porque está diretamente relacionada à construção do conceito de aprendizagem e de escola na estrutura "Condições Posteriores", desta forma, optamos por readequá-la e remanejá-la, já que pode complementar questões anteriores.

Considerando a dinâmica da entrevista e o material que disponibilizou para análise, optamos por também adicionar uma questão, compreendendo que complementaria o conjunto de informações suscitadas pelas demais já inseridas no 
roteiro, ao permitir a reflexão do participante quanto a panorama de ensino e aprendizagem que acabara de dissertar durante a entrevista.

Neste sentido, somamos ao roteiro a seguinte questão: Como você gostaria que fosse a aula de história? (Como você gostaria que o professor ensinasse?)

O resultado da análise das perguntas, bem como as adequações construídas a partir desta, pode ser observado na tabela seguinte:

Tabela 2 - Adequações individuais resultantes da análise das perguntas aos alunos ${ }^{5}$

\begin{tabular}{|c|c|c|c|c|}
\hline \multirow[t]{2}{*}{ QUESTÃO INICIAL } & \multicolumn{3}{|c|}{$\begin{array}{l}\text { ÍNDICE DE } \\
\text { CONCORDÂNCIA }\end{array}$} & \multirow[t]{2}{*}{ ADEQUAÇÃ̃O } \\
\hline & $\mathbf{R}$ & $\mathbf{C}$ & $\mathbf{O}$ & \\
\hline 1. Você gosta de ir para a escola? & $3 / 3$ & $3 / 3$ & $3 / 3$ & $\begin{array}{l}\text { Você gosta de ir para a escola? } \\
\text { Por que você (não) gosta de ir para a escola? }\end{array}$ \\
\hline $\begin{array}{l}\text { 2. O que você gosta de fazer na } \\
\text { escola? }\end{array}$ & $3 / 3$ & $3 / 3$ & $3 / 3$ & Não houve \\
\hline 3. Você tem muitos amigos lá (aqui)? & $3 / 3$ & $3 / 3$ & $3 / 3$ & Não houve \\
\hline 4. Você estuda muito lá? & $2 / 3$ & $2 / 3$ & $2 / 3$ & \multirow{3}{*}{$\begin{array}{l}\text { Agora nós vamos falar um pouco sobre quem } \\
\text { nos ajuda a aprender na escola e o que nós } \\
\text { estudamos lá, tudo bem?... }\end{array}$} \\
\hline $\begin{array}{l}\text { 5. Que matérias você estuda na } \\
\text { escola? }\end{array}$ & $2 / 3$ & $2 / 3$ & $2 / 3$ & \\
\hline 6. Como são os seus professores? & $1 / 3$ & $1 / 3$ & $1 / 3$ & \\
\hline $\begin{array}{l}\text { 7. Qual matéria você gosta mais? Por } \\
\text { quê? }\end{array}$ & $2 / 3$ & $2 / 3$ & $2 / 3$ & $\begin{array}{l}\text { Qual matéria você gosta mais? } \\
\text { Por quê? }\end{array}$ \\
\hline $\begin{array}{l}\text { 8. E qual matéria você não gosta de } \\
\text { estudar? Por quê? }\end{array}$ & $3 / 3$ & $3 / 3$ & $3 / 3$ & $\begin{array}{l}\text { E qual matéria você não gosta de estudar? Por } \\
\text { quê? }\end{array}$ \\
\hline 9. Você gosta das aulas de história? & $3 / 3$ & $3 / 3$ & $3 / 3$ & Você gosta das aulas de história? \\
\hline $\begin{array}{l}\text { 10. Quem é o seu professor (a) de } \\
\text { história? }\end{array}$ & $2 / 3$ & $2 / 3$ & $2 / 3$ & $\begin{array}{c}\text { Você lembra quem é seu professor de } \\
\text { história? Geralmente o professor faz várias } \\
\text { coisas na sala de aula para nós aprendermos, } \\
\text { não é verdade?... }\end{array}$ \\
\hline $\begin{array}{l}\text { 11. Fale um pouco desta aula... } \\
\text { Como o professor (a) faz pra } \\
\text { ensinar? }\end{array}$ & $3 / 3$ & $3 / 3$ & $3 / 3$ & Não houve \\
\hline 12. Você está aprendendo história? & $3 / 3$ & $3 / 3$ & $3 / 3$ & Não houve \\
\hline $\begin{array}{l}\text { 13. Como você faz pra lembrar o que } \\
\text { o professor de história ensinou? }\end{array}$ & $3 / 3$ & $3 / 3$ & $3 / 3$ & Não houve \\
\hline $\begin{array}{l}\text { 14. Você é bom aluno em história? } \\
\text { Por quê? }\end{array}$ & $2 / 3$ & $2 / 3$ & $2 / 3$ & Não houve \\
\hline $\begin{array}{l}\text { 15. Como o professor faz para saber } \\
\text { o que vocês aprenderam? }\end{array}$ & $2 / 3$ & $2 / 3$ & $2 / 3$ & Não houve \\
\hline $\begin{array}{l}\text { 16. E o que você já aprendeu na aula } \\
\text { de história? }\end{array}$ & $2 / 3$ & $1 / 3$ & $1 / 3$ & Não houve \\
\hline $\begin{array}{l}\text { 17. Você estuda em grupo ou } \\
\text { sozinho? }\end{array}$ & $2 / 3$ & $2 / 3$ & $2 / 3$ & $\begin{array}{c}\text { Remanejada e readequada: } \\
\text { E quando você está estudando na escola, } \\
\text { como você prefere? Em grupo ou sozinho? E } \\
\text { você sempre estuda em grupo (sozinho)? }\end{array}$ \\
\hline Pergunta adicionada & - & - & - & $\begin{array}{c}\text { Como você gostaria que fosse a aula de } \\
\text { história? (Como você gostaria que o professor } \\
\text { ensinasse?) }\end{array}$ \\
\hline
\end{tabular}

${ }^{5}$ Não se encontram numeradas tendo em vista adequações também realizadas quanto à ordem das perguntas. 
Fonte: Elaboração própria.

\section{Análise da entrevista com o professor}

O contato inicial com P1 ocorreu na sala dos professores de uma unidade escolar pertencente à Diretoria Regional de Educação estudada.

A participante expressou inicialmente certa preocupação quanto às perguntas, esclarecendo não ter experiência em ensino de história para alunos com deficiência intelectual.

A preocupação de P1 é expressão da grande e comum dificuldade de conceituação quanto à deficiência intelectual, objeto de controvérsias discutidas em inúmeros estudos 6 .

Diante da dúvida, apresentamos os dados de A1 constantes do Mapa de Atendimento fornecido pela DRE. Após atenta observação e análise das informações, P1 aceitou participar da entrevista.

\section{Quanto ao espaço e procedimentos para realização da entrevista}

A entrevista se iniciou às 16 horas e 7 minutos, terminando às 16 horas e 34 minutos, resultando em ampla quantidade de material de análise.

Havia inicialmente a preocupação do pesquisador quanto a possíveis interrupções, já que o espaço disponibilizado para entrevista foi a sala dos professores, espaço de uso comum aos docentes e funcionários da unidade escolar.

Tendo em vista que no contato inicial a participante havia esclarecido que os professores estavam saindo da reunião de $\mathrm{HTPC}^{7}$, consideramos não haver problemas para realização dos procedimentos neste espaço, o que não foi confirmado.

O primeiro item de interferência observado ocorreu devido a duas expressivas interrupções, sendo a primeira de 49 segundos e a segunda de 21 segundos, ambas, decorrentes da chegada e pequenos diálogos dirigidos por outros professores à participante.

E - Então como a $\mathrm{Sr}^{\mathrm{a}}$. realiza a avaliação do aprendizado destes alunos?

${ }^{6}$ Sobre o tema ver MENDES (1995).

${ }^{7}$ A sigla significa Horário de Trabalho Pedagógico Coletivo. Trata-se de reunião comum no estado de São Paulo, realizada entre direção, coordenação pedagógica e professores para discussão de itens relacionados ao cotidiano escolar. 
P1 - [...] você tem que gravar o que é Constituição, não importa se você vai decorar ou se você vai assimilar o que você entendeu, mas eu quero que você dê porque sem argumento não vai chegar a lugar nenhum... então eles falam o que é Constituição daí ele faz uma pergunta pra este entendeu? Dentro do tema... e assim vai... então... nós... coisas que daí eu estava explicando eles falam ah professora! Agora eu sei o que é República! Agora eu sei o que é Oligarquia entendeu?

Nesta primeira interrupção, a descontinuidade e dificuldade de organização do

discurso (grifo) indicam possível quebra de atenção da participante provocado no exato momento de chegada de outro professor ao espaço de execução da entrevista.

O mesmo parece ocorrer na segunda interrupção, quando a participante não consegue retomar a ordem do discurso (grifo) que desenvolvia para responder à pergunta do entrevistador.

E - Com a matrícula dos alunos com deficiência mental, houve alguma mudança quanto ao seu método de ensino?

P1 - [...] é porque ele tem que ser incluído, não excluído... Se eu estiver fazendo uma coisa especial pra ele precisa de uma escola que seja especial...

Apesar de não ter ocorrido a permanência destes professores no espaço de realização da entrevista, percebemos que a interrupção ou mesmo o movimento de chegada e saída acabou ocasionando comprometimento da mesma.

Desta forma, concluímos que as entrevistas deverão ser realizadas em espaço seguro de possíveis interrupções, devendo ainda ser vetada a presença de terceiros.

$\mathrm{O}$ segundo item de interferência pode ser observado na resposta às perguntas $2 \mathrm{e}$ 12.

E - Como a Sra . definiria "História"?

P1 - Bom, pra definir história acho que história é super importante... é... até mesmo porque o aluno, porque nós historiadores, nós professores de história, nós temos que ter um intuito de que história nós temos que formar um cidadão crítico né [...], prá gente poder desenvolver esse sentimento, de que o aluno tem que ser um agente, não passivo, mas ativo na sociedade, no meio em que ele vive né, transformando as relações... ele poder criticar, ter argumento, eu acho fundamental isso.

E - Ok. A $\mathrm{Sr}^{\mathrm{a}}$. poderia descrever como é que a $\mathrm{Sr}^{\mathrm{a}}$. faz para ensinar história aos alunos com deficiência mental?

P1 - Ai meu Deus... é complicado... olha sinceramente não sei se você tem problema aqui, mas eu sinceramente me sinto como eu já descrevi pra você... tem hora que não adianta... você não consegue atingi-lo... 
No contato inicial com P1, além dos objetivos da entrevista, também foi apresentada a função profissional do pesquisador, enquanto professor de história pesquisador de tema relacionado ao ensino da disciplina na escola regular.

No exemplo extraído da entrevista (grifo) podemos perceber que houve reconhecimento desta identidade funcional.

Conforme indicado na análise da entrevista com A1, estas informações prestadas no inicio dos procedimentos tem, de fato, o potencial de interferência no resultado da entrevista. É o que podemos observar na resposta de P1 à pergunta 5, que aborda tema relacionado a processos de avaliação do aprendizado.

E - Então como a $\mathrm{Sr}^{\mathrm{a}}$. realiza a avaliação do aprendizado destes alunos?

P1 - Então, primeiramente a avaliação.. é claro que a avaliação eu acho importante a escrita, né...porque quando a gente vai avaliar o aluno você tem que saber...

Diversas publicações sobre o ensino e aprendizagem de história (GUSMÃO, 2004; NIKITIUK, 2004; BITTENCOURT, 2005) têm questionado o tradicionalismo da exposição oral de conteúdos não significativos que devem ser decorados para reprodução em provas escritas que não proporcionam condições de reflexão próprias à disciplina em questão.

Esta discussão está particularmente presente na formação dos professores de história desde as primeiras propostas de reforma da abordagem historiográfica provocada pela publicação da revista Annales d'histoire économique et sociale, conduzida pelos historiadores franceses Lucien Febvre e March Bloch em 1929.

As publicações apresentadas pela revista questionavam a tradicional escrita da história reduzida à reprodução de grandes nomes, feitos e datas, propondo segundo Burke (1997) a substituição da narrativa pela chamada história-problema, a observação e análise das atividades humanas em contraposição à história política e o diálogo com as demais ciências visando à ampliação de compreensões acerca dos fenômenos estudados.

A discussão promovida pelos Annales, ainda hoje amplamente difundida e conhecida pelos historiadores, tornou-se essência da crítica contemporânea ao ensino desta história tradicional, cujos moldes de avaliação escrita transparecem no discurso de P1. 
Se retomarmos a análise anterior, quando percebemos o reconhecimento da função profissional do pesquisador, poderemos então inferir que diante disto a pergunta poderia ocasionar insegurança de resposta à participante.

A hipótese se confirma quando percebemos mudança de seu comportamento diante da pergunta, pois P1 passou a demonstrar apreensão no desenvolvimento da resposta, emitida em forma de explicação quanto ao procedimento (avaliação escrita), com volume de voz distinto do padrão utilizado durante toda a entrevista.

Desta forma, concluímos que o conhecimento da função profissional do pesquisador novamente ocasionou comprometimento da amostra, o que demandará aos procedimentos posteriores a devida omissão desta informação.

\section{Quanto às perguntas criadas para a compreensão do fenômeno estudado}

O mesmo quadro de julgamentos quanto à relevância, clareza e objetividade das questões foi encaminhado para análise dos professores de história convidados. Seguem os resultados:

Tabela 2 - Resultado da consulta aos professores quanto às perguntas a serem realizadas aos professores participantes

\begin{tabular}{ccccccc}
\hline \multirow{2}{*}{ Pergunta } & \multicolumn{2}{c}{ Relevância } & \multicolumn{2}{c}{ Clareza } & \multicolumn{2}{c}{ Objetividade } \\
\cline { 2 - 6 } & $\mathbf{S}$ & $\mathbf{N}$ & $\mathbf{S}$ & $\mathbf{N}$ & $\mathbf{S}$ & $\mathbf{N}$ \\
$\mathbf{1}$ & 3 & 0 & 2 & 1 & 2 & 1 \\
$\mathbf{2}$ & 3 & 0 & 2 & 1 & 2 & 1 \\
$\mathbf{3}$ & 3 & 0 & 3 & 0 & 3 & 0 \\
$\mathbf{4}$ & 3 & 0 & 3 & 0 & 3 & 0 \\
$\mathbf{5}$ & 3 & 0 & 3 & 0 & 3 & 0 \\
$\mathbf{6}$ & 3 & 0 & 3 & 0 & 3 & 0 \\
$\mathbf{7}$ & 2 & 1 & 2 & 0 & 2 & 0 \\
$\mathbf{8}$ & 2 & 1 & 2 & 0 & 2 & 0 \\
$\mathbf{9}$ & 2 & 1 & 2 & 0 & 2 & 0 \\
$\mathbf{1 0}$ & 3 & 0 & 3 & 0 & 3 & 0 \\
$\mathbf{1 1}$ & 3 & 0 & 3 & 0 & 3 & 0 \\
$\mathbf{1 2}$ & 3 & 0 & 3 & 0 & 3 & 0 \\
$\mathbf{1 3}$ & 3 & 0 & 3 & 0 & 3 & 0 \\
$\mathbf{1 4}$ & 3 & 0 & 3 & 0 & 3 & 0 \\
$\mathbf{1 5}$ & 2 & 1 & 2 & 0 & 2 & 0 \\
$\mathbf{1 6}$ & 3 & 0 & 3 & 0 & 3 & 0 \\
\hline $\mathbf{1 7}$ & 2 & 1 & 2 & 0 & 2 & 0 \\
\hline $\mathbf{F}$ & 3 & & & & & \\
$\mathbf{1 0}$ & 3 & 0 & 0 & 0 & 0 \\
\hline
\end{tabular}

Fonte: Elaboração própria. 
A pergunta 1 obteve alto índice de concordância quanto à sua relevância, porém a resposta de P1 demonstrou-se evasiva, não oferecendo fundamental informação referente à importância do ensino de história.

Visando a aumentar a objetividade da pergunta com menor foco sobre o entrevistado, decidimos por adequá-la, o que resultou em nova disposição: Hoje, que importância é atribuída à disciplina de história? Por quê?

O mesmo ocorre quanto às perguntas 2 e 3 , com alto índice de concordância quanto à relevância para o estudo, porém respondidas de forma evasiva pela participante, não oferecendo informações fundamentais para compreensão do conceito de história e dos requisitos mínimos para aprendizagem em história.

Com o mesmo intuito anterior, decidimos adequar as perguntas, resultando: Como poderia ser definida a História no ensino fundamental? Quais habilidades dos alunos melhor contribuem para o aprendizado de história?

As perguntas 4 e 5 também foram julgadas de alta relevância para o estudo. Observando as respostas de P1, é possível perceber a constituição de notáveis elementos para análise, contribuindo para a compreensão do método de ensino e avaliação dos alunos, o que nos leva a concluir que ambas cumprem plenamente sua função, devendo ser mantidas sem alteração.

A pergunta 6 também obteve alto índice de concordância quanto à sua relevância. A análise da resposta indica, porém, a necessidade de complementação da pergunta visando a proporcionar condições para que o participante ofereça maiores detalhes sobre a concepção de êxito.

Analisando as possibilidades de adequação, concluímos pela inviabilidade de uma complementação padronizada, já que estaria diretamente relacionada ao conteúdo da resposta. Desta forma, concluímos pela manutenção da pergunta seguida do complemento sugerido entre parênteses (Por quê?).

As perguntas 7, 8, e 9, com médio índice de concordância, representam o item "Preparo Profissional", como indicado anteriormente, não significativo para o desenvolvimento do estudo.

Quanto ao conteúdo das perguntas, a primeira tem por objetivo verificar item inerente à subjetividade do professor, podendo somar-se às demais para a compreensão do conceito de deficiência. 
Observando mais detidamente, podemos perceber que acaba por cumprir função sugestiva (LODI, 1971) podendo conduzir a uma resposta esperada, já que traz a premissa de que há resistência quanto à matrícula de alunos com deficiência na escola regular.

O mesmo pode ser observado nas perguntas seguintes quanto ao preparo para recebê-las, trazendo consigo a ideia de que, de fato, este procedimento é anterior e se faz necessário. Diante da análise, decidimos por excluí-las.

As perguntas 10 e 11 dão início às primeiras questões representando as condições posteriores à matrícula e frequência dos alunos com deficiência intelectual. Os resultados observados nas respostas de P1 são positivos e permitem análise de vários itens importantes para o estudo, o que, somado ao julgamento positivo dos professores consultados, leva-nos a concluir pela sua manutenção com adequação resumida aos conceitos presentes, passando a ser utilizado deficiência intelectual.

O mesmo ocorre quanto às perguntas 12,13, 14 e 15 que tratam respectivamente do ensino, avaliação, êxito e experiência exitosa no ensino de história para os alunos com deficiência intelectual, que, obtendo alto índice de concordância quanto a sua relevância, além de compreensão e clareza observada na resposta de P1, nos levam a concluir pela sua manutenção, sendo adequado somente o conceito utilizado nas perguntas 12,13 e 14, passando a constar deficiência intelectual.

A pergunta 16 obteve médio índice de concordância quanto a sua relevância. Visa à reflexão do professor quanto a práticas pedagógicas em história sob perspectiva inclusiva.

Não houve resposta de $\mathrm{P} 1$ à proposta reflexiva, o que nos levou a questionar as possibilidades de adequação que garantam melhores condições para a aquisição da resposta. Desta forma, buscamos torná-la mais clara, garantindo a percepção do professor quanto à importância de sua contribuição para a prática pedagógica de outros professores que tiverem acesso ao trabalho desenvolvido, o que resultou no seguinte dispositivo:

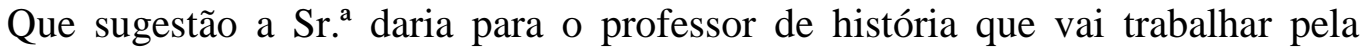
primeira vez com alunos com deficiência intelectual?

A pergunta 17 obteve médio índice de concordância. Cumpre na realidade uma função ética no roteiro, visando a abrir espaço para a participação livre do entrevistado quanto a qualquer item que deseje complementar ou mesmo discutir. Visando a melhor 
contextualizar seu objetivo no roteiro, optamos por não numerá-la enquanto pergunta descendente dos itens estruturais.

O resultado da análise das perguntas, bem como as adequações construídas a partir desta, pode ser observado no quadro seguinte:

\section{Quadro 3 - Adequações individuais resultantes da análise das perguntas aos} professores

\begin{tabular}{|c|c|c|c|c|}
\hline \multirow{2}{*}{ QUESTÃO INICIAL } & \multicolumn{3}{|c|}{\begin{tabular}{c|} 
Índice de \\
Concordância \\
\end{tabular}} & \multirow{2}{*}{ ADEQUAÇÃO } \\
\hline & $\mathbf{R}$ & $\mathbf{C}$ & $\mathbf{O}$ & \\
\hline 1. Como o Sr. (a) definiria "História"? & $3 / 3$ & $2 / 3$ & $2 / 3$ & $\begin{array}{c}\text { Como poderia ser definida a História no ensino } \\
\text { fundamental? }\end{array}$ \\
\hline $\begin{array}{l}\text { 2. Para o Sr. (a) qual seria a importância do } \\
\text { ensino de história no Ensino Fundamental? }\end{array}$ & $3 / 3$ & $2 / 3$ & $2 / 3$ & $\begin{array}{l}\text { Hoje, que importância é atribuída à disciplina de } \\
\text { história para o ensino fundamental? Por quê? }\end{array}$ \\
\hline $\begin{array}{l}\text { 3. O que o Sr. (a) considera fundamental } \\
\text { para que o aluno possa aprender história? }\end{array}$ & $3 / 3$ & $3 / 3$ & $3 / 3$ & $\begin{array}{l}\text { Quais habilidades dos alunos, melhor contribuem } \\
\text { para o aprendizado de história? }\end{array}$ \\
\hline $\begin{array}{l}\text { 4. O Sr. (a) poderia descrever como faz } \\
\text { para ensinar história aos seus alunos? }\end{array}$ & $3 / 3$ & $3 / 3$ & $3 / 3$ & Não houve \\
\hline $\begin{array}{l}\text { 5. Como o Sr. (a) realiza a avaliação do } \\
\text { aprendizado de seus alunos? }\end{array}$ & $3 / 3$ & $3 / 3$ & $3 / 3$ & Não houve \\
\hline $\begin{array}{l}\text { 6. Quando o Sr. (a) considera ter alcançado } \\
\text { êxito no ensino de história para seus } \\
\text { alunos? }\end{array}$ & $3 / 3$ & $3 / 3$ & $3 / 3$ & $\begin{array}{l}\text { Quando o Sr. (a) considera ter alcançado êxito no } \\
\text { ensino de história para seus alunos? (Por quê?) }\end{array}$ \\
\hline $\begin{array}{l}\text { 7. Podemos ver um grande crescimento no } \\
\text { número de matrícula de alunos com } \\
\text { deficiência nas escolas regulares. Poderia } \\
\text { descrever como foi para o Sr. (a) receber a } \\
\text { primeira noticia de que teria um aluno com } \\
\text { deficiência mental na sala de aula? }\end{array}$ & $2 / 3$ & $2 / 3$ & $2 / 3$ & Excluída. \\
\hline $\begin{array}{l}\text { 8. Àquele momento, o Sr. (a) acredita que } \\
\text { estava preparado para recebê-lo? Por quê? }\end{array}$ & $2 / 3$ & $2 / 3$ & $2 / 3$ & Excluída. \\
\hline $\begin{array}{l}\text { 9. Foi oferecido algum treinamento sobre o } \\
\text { ensino de alunos com deficiência mental? }\end{array}$ & $2 / 3$ & $2 / 3$ & $2 / 3$ & Excluída. \\
\hline $\begin{array}{c}\text { 10. Com a matrícula dos alunos com } \\
\text { deficiência mental, houve alguma mudança } \\
\text { quanto ao seu método de ensino? }\end{array}$ & $3 / 3$ & $3 / 3$ & $3 / 3$ & $\begin{array}{l}\text { Com a matrícula dos alunos com deficiência } \\
\text { intelectual, houve alguma mudança quanto ao seu } \\
\text { método de ensino? }\end{array}$ \\
\hline $\begin{array}{c}\text { 11. O que o Sr. (a) considera fundamental } \\
\text { para que o aluno com deficiência mental } \\
\text { possa aprender história? }\end{array}$ & $3 / 3$ & $3 / 3$ & $3 / 3$ & $\begin{array}{l}\text { O que o Sr. (a) considera fundamental para que o } \\
\text { aluno com deficiência intelectual possa aprender } \\
\text { história? }\end{array}$ \\
\hline $\begin{array}{c}\text { 12. O Sr. (a) poderia descrever como faz } \\
\text { para ensinar história aos seus alunos com } \\
\text { deficiência mental? }\end{array}$ & $3 / 3$ & $3 / 3$ & $3 / 3$ & $\begin{array}{c}\text { O Sr. (a) poderia descrever como faz para ensinar } \\
\text { história aos seus alunos com deficiência } \\
\text { intelectual? }\end{array}$ \\
\hline $\begin{array}{l}\text { 13. Como o Sr. (a) realiza a avaliação do } \\
\text { aprendizado de seus alunos com deficiência } \\
\text { mental? }\end{array}$ & $3 / 3$ & $3 / 3$ & $3 / 3$ & $\begin{array}{l}\text { Como o Sr. (a) realiza a avaliação do aprendizado } \\
\text { de seus alunos com deficiência intelectual? }\end{array}$ \\
\hline $\begin{array}{l}\text { 14. Quando o Sr. (a) considera ter } \\
\text { alcançado êxito no ensino de história para } \\
\text { os alunos com deficiência mental? }\end{array}$ & $3 / 3$ & $3 / 3$ & $3 / 3$ & $\begin{array}{l}\text { Quando o Sr. (a) considera ter alcançado êxito no } \\
\text { ensino de história para os alunos com deficiência } \\
\text { intelectual? }\end{array}$ \\
\hline $\begin{array}{l}\text { 15. Poderia descrever qual foi a sua melhor } \\
\text { experiência de ensino de história para este } \\
\text { aluno? }\end{array}$ & $2 / 3$ & $2 / 3$ & $2 / 3$ & Não houve \\
\hline $\begin{array}{c}\text { 16. Tem alguma sugestão relacionada ao } \\
\text { Ensino de História para alunos com } \\
\text { deficiência mental? }\end{array}$ & $3 / 3$ & $3 / 3$ & $3 / 3$ & $\begin{array}{l}\text { Que sugestão a Sr. }{ }^{\text {a }} \text { daria para o professor de } \\
\text { história que vai trabalhar pela primeira vez com } \\
\text { alunos com def. intelectual? }\end{array}$ \\
\hline $\begin{array}{l}\text { 17. Há alguma informação que o Sr. (a) } \\
\text { deseja esclarecer? }\end{array}$ & $2 / 3$ & $2 / 3$ & $2 / 3$ & $\begin{array}{c}\text { Há alguma informação que o Sr. (a) deseja } \\
\text { esclarecer? }\end{array}$ \\
\hline
\end{tabular}

Fonte: Elaboração própria. 


\section{Considerações finais}

Após minuciosa análise dos métodos e procedimentos para coleta de dados, concluímos ter alcançado um sugestivo resultado qualitativo na busca pela garantia da cientificidade e sustentabilidade às fontes disponibilizadas para análise. Assim sendo, entendemos que a utilização do projeto piloto como mecanismo de análise tanto dos procedimentos quanto das ferramentas construídas pelo pesquisador para o desenvolvimento do processo de coleta de dados, visando constituir os fundamentos necessários para o debate a que se propõe na pesquisa, é de fundamental importância e garante significativa ampliação da qualidade das fontes construídas para a construção do conhecimento científico.

\section{CONTRIBUTIONS OF THE PILOT PROJECT ON THE COLLECTION OF DATA} ON RESEARCH IN THE AREA OF EDUCATION

ABSTRACT: In this article deal with the importance of the pilot project as a key resource for planning and analysis procedures that will be adopted in the construction of truly scientific sources through interviews. To this end, we present the entire trajectory of planning, implementation, analysis and restructuring of the interviews that we use as a resource for data collection in a dissertation whose focus was the analysis of the conception of success in teaching history for students with intellectual disabilities in a Regional Board of education of the State of São Paulo in Brazil. The results showed that the interview is in fact an important resource for gathering data on research involving the participation of students with intellectual disabilities, however, needs to be widely planned in order to reduce the chance of interference from several factors which, by their very nature, are capable of compromising the sample and therefore, the trustworthiness expected in academic papers.

KEYWORDS: Interview. Feature. Pilot project.

\section{REFERÊNCIAS}

BITTENCOURT, C. (Org.). O saber histórico na sala de aula. São Paulo: Contexto, 2005.

BURKE, P. A escola dos annales (1929-1989): a revolução francesa da historiografia. São Paulo: Ed. da UNESP, 1997.

CRUZ, M. B. A. O ensino de história no contexto das transições paradigmáticas da história e da educação. In: NIKITIUK, S. L. (Org.). Repensando o ensino de história. São Paulo: Cortez, 2004. p.73-83.

DIAS, T. R. S.; OMOTE, S. Entrevista em educação especial: aspectos metodológicos. Revista Brasileira de Educação Especial, Marília, v.3, p.93-100, 1995. 
Entrevista em educação especial: a natureza dos problemas investigados.

Temas em Educação Especial, São Carlos, v.1, p.67-80, 1990.

GUSMÃO, E. M. Memórias de quem ensina história: cultura e identidade docente. São Paulo: Ed. da UNESP, 2004.

LODI, J. B. A Entrevista: teoria e prática. São Paulo: Pioneira, 1971.

MENDES, E. G. Deficiência mental: a construção científica de um conceito e a realidade educacional. 1995. 387f. Tese (Doutorado em Psicologia) - Instituto de Psicologia, Universidade de São Paulo, 1995.

MOLL, L. C. Vygotsky e a educação: implicações pedagógicas na psicologia sóciohistórica. Porto Alegre: Artes Médicas, 1996.

MORAES, R. Uma Tempestade de Luz: a compreensão possibilitada pela análise social discursiva. Ciência e Educação, São Paulo, v.9, n.2, p.191-211, 2003.

NIKITIUK, S. L. (Org.). Repensando o ensino de história. São Paulo: Cortez, 2004.

OLIVEIRA, A. A. S. A entrevista em educação especial: questões metodológicas. In: MARQUEZINE, M. C.; ALMEIDA, M. A.; OMOTE, S. Colóquios sobre pesquisa em educação especial. Londrina: EDUEL, 2003. p.27-41.

PADILHA, A. M. L. Possibilidades de história ao contrário: ou como desencaminhar o aluno da classe especial. 3.ed. São Paulo: Plexus, 2004.

VYGOTSKY, L. S. Pensamento e linguagem. São Paulo: Martins Fontes, 1999. Obras escogidas: fundamentos da defectologia. Madri: Visor, 1997. v.5. 